\title{
Caracterización de las antocianinas de la flor de ceibo como sensibilizadores naturales para su uso en celdas fotovoltaicas
}

\section{Characterization of anthocyanins from ceibo flower as natural sensitizers in photovoltaic cells}

\author{
Cerdá, María Fernanda (1), Enciso, Paula (1). \\ (1)Laboratorio de Biomateriales, Facultad de Ciencias, Universidad de la República, UdelaR, Montevideo, Uruguay. \\ Contacto: fcerda@fcien.edu.uy \\ RECIBIDO: 14/05/2014 - APROBADO: 9/10/2014
}

\begin{abstract}
Resumen
La energía solar es la fuente de energía más promisoria del futuro. La conversión directa de luz solar en energía eléctrica mediante el uso de celdas solares posee muchas ventajas sobre los métodos usados en la actualidad, debido a que no genera desechos o contaminantes.

En particular, las celdas solares sensibilizadas con pigmentos (DSSC) o celdas de Graetzel representan una alternativa a las convencionales celdas solares de silicio. En las últimas tres décadas han atraído considerable atención como una forma de producir celdas fotovoltaicas de bajo costo dada la posibilidad de alcanzar con ellas una alta eficiencia de conversión (de aproximadamente 12\%) y su alto rendimiento durante períodos de luz prolongados e incluso en condiciones de stress térmico.

En este trabajo se evalúan pigmentos de origen natural, la mezcla de antocianinas provenientes de la flor del ceibo, como sensibilizadores de estas celdas. Se utilizan medidas de absorbancia UV-visible, voltamperometría cíclica y espectroscopía de impedancia electroquímica como forma de caracterización.

Palabras clave: Antocianinas, sensibilizadores, DSSC.
\end{abstract}

\begin{abstract}
Solar energy is the promising font of the future. Direct conversion of solar light into electricity using solar cells has many advantages, arising from the fact that does not generate contaminants or waste.

Particularly, dye sensitized solar cells (DSSC) or Graetzel cells represent an alternative to conventional silicon ones. In the three last decades DSSC have attracted great attention because of their low cost, the achievement of high efficiency conversion (12\%), and good yields during prolonged light periods and under thermal stress.

In this work, a mixture of natural dyes, anthocyanins from ceibo flower, is evaluated for their use as sensitizers. UV-visible measurements, cyclic voltammetry and electrochemical impedance spectroscopy are used to characterize these dyes.

Keywords: Anthocyanin, sensitizers, DSSC.
\end{abstract}

\section{Introducción}

La obtención de energía a partir de recursos fósiles genera problemas relacionados con la limitada disponibilidad de los mismos y las desastrosas consecuencias ambientales de su uso masivo. Esto ha llevado a un aumento en el interés por el desarrollo de fuentes alternativas de energía renovables que sean capaces de satisfacer la demanda global energética. Entre las fuentes de energía posibles, la solar es la más promisoria del futuro, ya que la conversión directa de luz solar en energía eléctrica mediante el uso de celdas solares posee muchas ventajas sobre los métodos usados en la actualidad, debido a que no genera desechos o contaminantes.

La producción de energía fotovoltaica se ha duplicado cada dos años desde 2002, haciendo de este el sector energé- tico que más rápidamente crece. Afortunadamente, Uruguay presenta niveles de radiación solar considerables, lo cual le otorga un atractivo adicional al uso de estas celdas (Abal, et al., 2011). Con respecto a la legislación, nuestro país cuenta con grandes avances en su marco jurídico, con normas aprobadas que contribuyen a la reglamentación ambiental. En referencia al marco energético, el Poder Ejecutivo ha aprobado que el $50 \%$ de la energía generada en el país debe provenir de fuentes renovables a 2015 , incluyendo un $25 \%$ proveniente de energías no convencionales (Uruguay, 2000; Uruguay, 2010). Sin embargo, los altos costos de estas tecnologías continúan siendo un problema difícil de afrontar.

En ese contexto, las celdas solares sensibilizadas con pigmentos (conocidas como celdas de Graetzel o DSSC) han atraído considerable atención en las últimas tres 
décadas como una forma promisoria de tecnología para producir celdas fotovoltaicas de bajo costo. Asimismo, estas celdas alcanzan una alta eficiencia de conversión (las más eficientes alcanzan valores de un $12 \%$ ), y tienen un alto rendimiento durante períodos de luz prolongados e incluso en condiciones de stress térmico (Gao, et al., 2008; Cao, et al., 2009; Chen, et al., 2009; Wang, et al., 2010; Yella, et al., 2011; Bisquert, et al., 2004).

Una celda DSSC típica contiene en el corazón del sistema una película de material semiconductor mesoporoso nanocristalino (en general $\mathrm{TiO}_{2}$, forma anatasa) cubierta con una monocapa de pigmentos coloreados capaces de sufrir procesos de transferencia de carga adsorbidos a la superficie del semiconductor. El semiconductor se deposita sobre un óxido transparente conductor (electrodo de FTO o de ITO), a través del cual se ilumina la celda, y se pone en contacto con una solución de electrolito que contiene una cupla redox $\left(\mathrm{I}^{-} / \mathrm{I}_{3}^{-}\right)$. El circuito se cierra con un electrodo de platino o carbono (Bisquert, et al., 2004; Ito, et al., 2007).

Al producirse la fotoexcitación del pigmento por la luz solar, el electrón es inyectado hacia la banda de conducción del semiconductor, moviéndose posteriormente hacia el sustrato de FTO o ITO. La regeneración del pigmento oxidado por reducción del mismo ocurre en el electrodo auxiliar, donde la cupla ioduro/tri-ioduro del electrolito aporta los electrones necesarios. Esto además previene la recaptura del electrón de la banda de conducción por el pigmento oxidado. El circuito se completa con la migración de electrones a través de los conectores externos.

En suma, el dispositivo genera energía eléctrica a partir de la luz solar sin sufrir ninguna transformación química permanente.

$\mathrm{El} \mathrm{TiO}_{2}$ es un semiconductor que posee una brecha energética ancha entre las bandas de valencia y de conductividad, de ca. $3 \mathrm{eV}$, dependiendo de la estructura cristalina que adopte (3.0 eV para el rutilo y $3.2 \mathrm{eV}$ para la anatasa). Esto le permite una absorción óptica en la región del UV (por debajo de los $400 \mathrm{~nm}$ ) que representa apenas un $10 \%$ del total del espectro solar. Todo material que posea una brecha más angosta y, por lo tanto, absorba en el visible o la región del infrarrojo puede usarse para sensibilizar materiales de $\mathrm{TiO}_{2}$. Así, varios materiales sensibilizadores pueden ser usados con este fin, como los semiconductores inorgánicos con brechas más angostas, metales y complejos metálicos (Imahori, et al., 2006; Scott, et al., 2007; O'Reagan, et al., 2007; Klahr, et al., 2009), y pigmentos orgánicos (Howie, et al., 2008; Fukuri, et al., 2006) sin despreciar los pigmentos de origen natural que también han sido muy estudiados (Calogero, et al., 2012; Hao, et al., 2006; Zhou, et al., 2011; Li, et al., 2013; Calogero y Di Marco, 2008; Al-Bat'hi, et al., 2013).

Para ser eficiente, el pigmento debe tener un coeficiente de extinción molar alto y un rango espectral ancho que le asegure la capacidad de absorber luz en el visible así como en el IR cercano. En segundo lugar, el potencial redox del pigmento debe ser suficientemente mayor que el valor de la banda de conducción del $\mathrm{TiO}_{2}$ para que sea posible el proceso de transferencia de electrones.

Por último, estos pigmentos deben presentar grupos funcionales capaces de unirse $\mathrm{al}_{\mathrm{TiO}_{2}}$ a través de interacciones covalentes, electrostáticas, enlaces por puente de hidrógeno o por fuerzas de van der Waals. La mayoría de los pigmentos usan para este fin sus grupos funcionales carboxilos e hidroxilos (Brumbach, et al., 2009).
Los pigmentos naturales constituyen una alternativa atrayente como fotosensibilizadores en celdas de Graetzel debido a su bajo costo y a la abundancia del recurso, lo que muestra a estas celdas como una opción atractiva en países con economías emergentes como el nuestro. Se han reportado trabajos con pigmentos naturales donde se alcanzan eficiencias nada despreciables de hasta un $2 \%$, pero donde los costos de las mismas y su estabilidad compiten con las de mayor eficiencia (Grätzel y Zakeeruddin, 2013; Yum, et al., 2012; Dwivedi, et al., 2013; Ito, et al., 2011).

Varios pigmentos han sido extraídos a partir de flores, hojas y frutas para ser utilizados en celdas solares de tipo DSSC, como las antocianinas, las clorofilas, las xantofilas, los flavonoides y los carotenos. Algunos de ellos presentan altos coeficientes de extinción $\left(105 \mathrm{l} \mathrm{mol}^{-1} \mathrm{~cm}^{-1}\right)$, lo que les confiere interesantes características para su uso como sensibilizadores (Calogero, et al., 2012).

Lo que se plantea en esta propuesta es la extracción y caracterización de las antocianinas provenientes de la flor del ceibo (Erythrina crista-galli), rica en este tipo de flavonoides (Yum, et al., 2012; Mitscher, et al., 1988; Miño y Ferraro, 2002). Las antocianinas son responsables del color rojo característico de esta flor, con un máximo de absorbancia a $530 \mathrm{~nm}$ (Scogin, 1991; Mazza and Miniati, 1993). Son compuestos polifénolicos que se encuentran en la naturaleza en forma de glicósidos y presentan grupos $\mathrm{OH}$ responsables de la unión con el $\mathrm{TiO}_{2}$ (Scogin, 1991; Mazza y Miniati, 1993). En esta flor en particular se encuentran mayoritariamente tres clases de antocianinas: cianidina 3-soforósido, cianidina 3-glucósido y pelargonidina 3-glucósido (Scogin, 1991), cuyas estructuras se observan en la Figura 1.

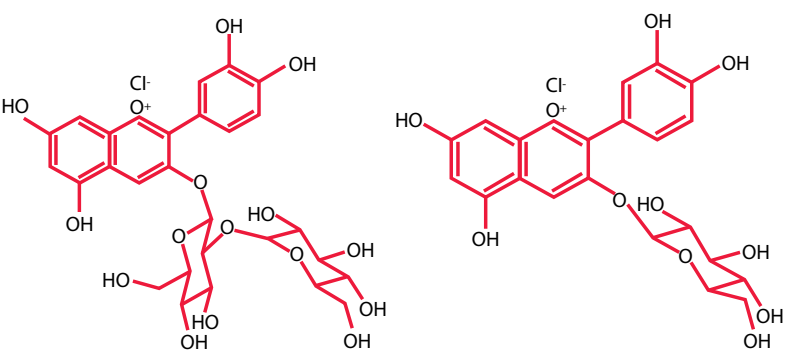

Figura 1. Estructura de antocianinas presentes en Erythrina crista-galli: cianidina 3-soforósido (izquierda), cianidina 3-glucósido (derecha).

También se evaluó la estabilidad de las antocianinas frente a varios parámetros físicos y químicos a los cuales se encontrarán expuestas al ser parte de la celda, entre ellos la temperatura y los componentes del electrolito ( $\mathrm{NaI}$ y etilenglicol).

Finalmente, se procedió al armado de celdas de tipo «sándwich», determinándose por espectroscopía de impedancia electroquímica sus cambios en el comportamiento en presencia y en ausencia de luz.

\section{Materiales y Métodos}

\section{Extracción de antocianinas}

Se utilizaron hojas de Erythrina crista-galli. Para obtener el extracto de antocianinas, $2 \mathrm{~g}$ de material vegetal seco fueron mortereados con $10 \mathrm{~mL}$ de etanol $95 \%$ a tempera- 
tura ambiente. Luego de filtrar el extracto, se volvió a tratar con $5 \mathrm{~mL}$ de solvente en iguales condiciones. Los filtrados fueron reunidos y llevados a sequedad bajo corriente de nitrógeno. La concentración total de antocianinas de los extractos utilizados en los estudios se determinó de acuerdo a $A_{530}-\left(0,25^{\star} A_{657}\right)$, que compensa la contribución de clorofila a la absorbancia a $530 \mathrm{~nm}$ (Rabino y Mancinelli, 1986; Akond, 2011).

\section{Caracterización de los pigmentos}

Se realizó la caracterización por voltamperometría cíclica de la mezcla de antocianinas (extracto $95 \%$ etanol) a una concentración de $0,1 \mathrm{mg} / \mathrm{mL}$. Se utilizó un electrodo de trabajo de $\mathrm{Au}-p c$ (policristalino, 0,0707 $\mathrm{cm}^{2}$ de área geométrica), un electrodo de referencia de $\mathrm{Ag} / \mathrm{AgCl}(\mathrm{E}=0,195 \mathrm{~V}$ vs. $\mathrm{ENH})$ y grafito como electrodo auxiliar. El electrolito soporte fue $\mathrm{NaClO}_{4}$ 0,05 M o mezcla al 50\% con etanol, y se aplicaron rutinas a diferentes velocidades de barrido de potencial situadas entre 0,01 y $0,1 \mathrm{Vs}^{-1}$.

La estabilidad térmica de las antocianinas fue evaluada en un rango de temperatura de entre $25^{\circ} \mathrm{C}$ y $90^{\circ} \mathrm{C}$ a través de medidas de absorbancia a $530 \mathrm{~nm}$, siguiendo la variación en los valores medidos. Para los estudios de estabilidad con respecto al $\mathrm{NaI}(0 \mathrm{M}-3 \mathrm{M})$ y al etilenglicol (mezclas en etanol dentro del rango $0 \%$ a $40 \%$ ) también se efectuaron medidas de absorbancia a igual longitud de onda.

\section{Caracterización electroquímica de la celda}

Se armaron celdas de tipo "sándwich», utilizando un electrodo de FTO (fluorine doped tin oxide) conteniendo al semiconductor y al pigmento como electrodo de trabajo, y como electrodo auxiliar FTO cubierto de grafito. El pigmento fue depositado por adsorción sobre el $\mathrm{TiO}_{2}$ nanoestructurado obtenido por aplicación directa de la pasta comercial (Degussa P-25) por doctor blade sobre el electrodo de vidrio conductor. El circuito se completó colocando entre ambos electrodos el etilenglicol conteniendo la cupla redox $\mathrm{I}^{-} / \mathrm{I}_{3^{-}}$(Smestad, 1998).

Una vez armada la celda, se procedió a su control por medidas de impedancia electroquímica, realizadas tanto en presencia de luz como en oscuridad. Estas medidas se realizaron en un rango de 0 a $700 \mathrm{mV}$, a frecuencias comprendidas entre $100 \mathrm{mHz}$ y $3 \mathrm{MHz}$.

\section{Resultados}

\section{Caracterización electroquímica de los pigmentos}

Con respecto a la caracterización electroquímica, se realizaron los perfiles voltamperométricos para el Au- $p c$ en electrolito soporte $\mathrm{NaClO}_{4} 0.05 \mathrm{M}$; en $\mathrm{NaClO}_{4} 0.05 \mathrm{M}$ y etanol $95 \%$ en iguales volúmenes; $y$ en presencia de las antocianinas del ceibo en mezcla etanol $95 \%-\mathrm{NaClO}_{4} 0.05 \mathrm{M}$. Grandes cambios fueron observados en los perfiles voltamperométricos en presencia de las antocianinas con respecto a los perfiles obtenidos en electrolito soporte. En ellos se observa una contribución anódica a $1.3 \mathrm{~V}$ con su pico catódico correspondiente en $0.6 \mathrm{~V}$, que no se encontraba presente en los perfiles provenientes del electrolito soporte o del etanol (Gráfico 1).

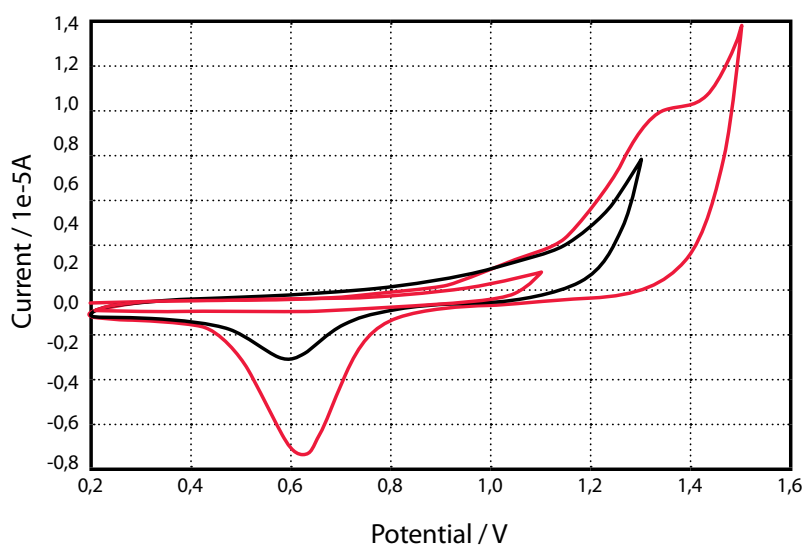

Gráfico 1. Voltamperogramas de Au- $p c$ en presencia del pigmento de ceibo (en etanol 95\%) y electrolito soporte $\mathrm{NaClO}_{4}$ a diferentes barridos de potencial.

\section{Estudios de estabilidad}

Los estudios de estabilidad se hicieron siguiendo el comportamiento a $530 \mathrm{~nm}$, longitud de onda en que las antocianinas presentan un máximo en el valor de absorbancia (Gráfico 2).

Con la temperatura se observaron dos situaciones: una primera región donde se observa un aumento en los valores de absorbancia al incrementar la temperatura desde $25^{\circ} \mathrm{C}$ a $60^{\circ} \mathrm{C}$, y una segunda región, correspondiente a las temperaturas más altas, donde los valores de absorbancia son similares, como se observa en el Gráfico 3.

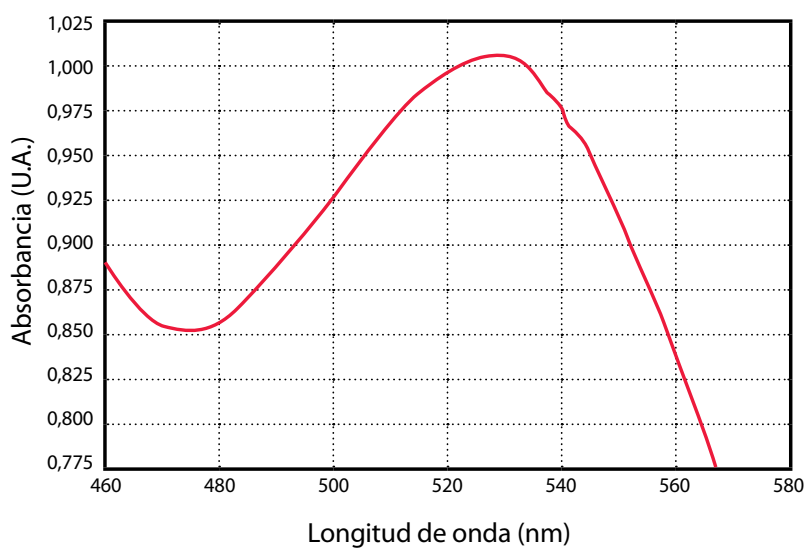

Gráfico 2. Espectro de absorbancia de una solución conteniendo una mezcla de antocianinas extraídas con etanol a partir de la flor del ceibo.

Respecto a la estabilidad del pigmento frente al NaI, se observó un aumento en los valores de absorbancia a $530 \mathrm{~nm}$ al incrementar la concentración de $\mathrm{NaI}$ desde $0 \mathrm{M}$ a 3,0 $\mathrm{M}$ (Gráfico 4).

Frente al etilenglicol, no se obtuvieron cambios significativos en los valores de absorbancia al incrementar el porcentaje del mismo. 


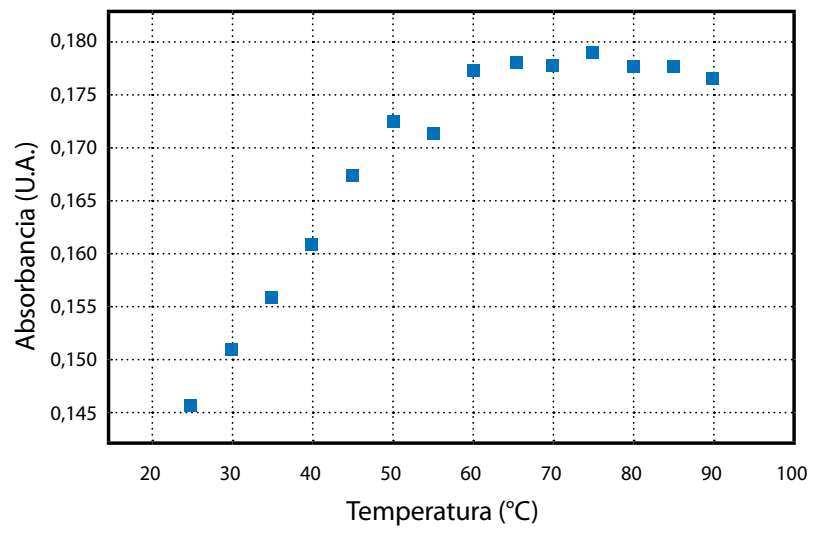

Gráfico 3. Evaluación del comportamiento de antocianinas frente al incremento de temperatura.

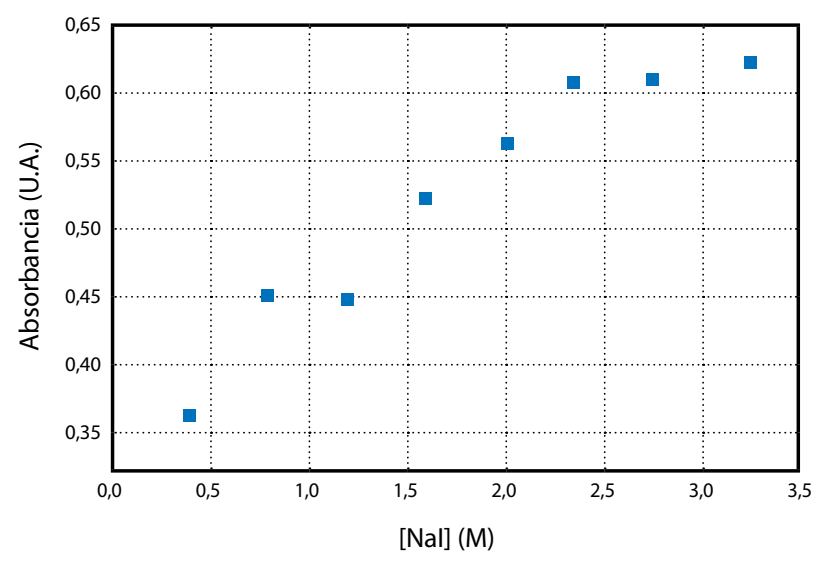

Gráfico 4. Evaluación del comportamiento de antocianinas frente al incremento de NaI.

\section{Estudios de impedancia}

Los resultados obtenidos por impedancia para las celdas que contienen el pigmento de color rojo fueron analizados utilizando un circuito como el que se muestra en la Figura 2 (Frabregat-Santiago, 2005).

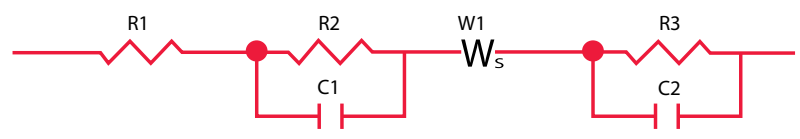

Figura 2. Circuito equivalente para una celda DSSC.

En este modelo los elementos $\mathrm{R} 2$ y C1 representan los procesos de transferencia de carga que ocurren sobre el electrodo de trabajo, mientras que $\mathrm{R} 3$ y C2 representan lo que ocurre sobre el electrodo auxiliar.

Analizando los valores medidos de acuerdo a este circuito, se pudo observar una gran disminución (a aproximadamente un valor final que representa el $1 \%$ del inicial) en los valores de R2 y una duplicación en los valores de la C1, al pasar de condiciones de oscuridad a condiciones de iluminación (con lámpara de led, potencia de 100 watts).
Esto puede apreciarse en forma muy clara al comparar los perfiles de impedancia medidos en ambas condiciones (Gráfico 5).

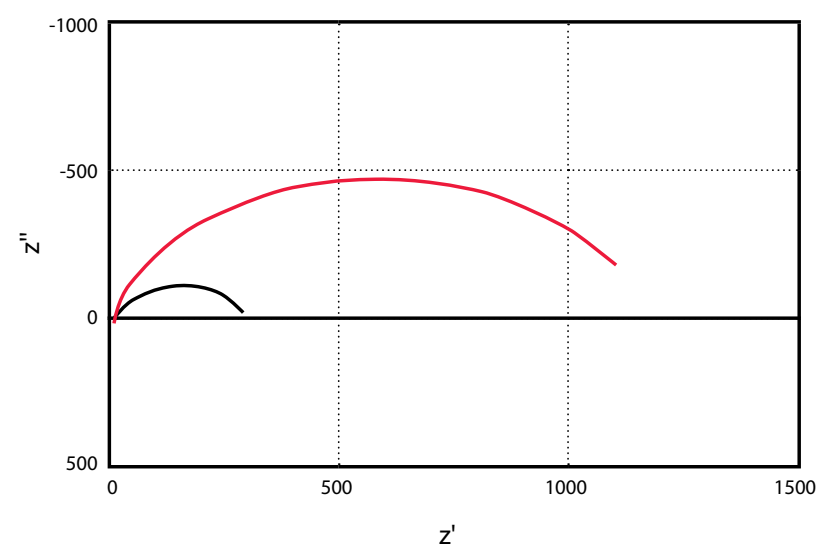

Gráfico 5. EIS de la celda armada en oscuridad (rojo) $y$ en presencia de luz (negro).

$\mathrm{E}_{\text {aplicado }}=-0.467 \mathrm{~V}$, grafito como electrodo auxiliar.

\section{Discusión}

\section{Caracterización electroquímica de los pigmentos}

Como se mencionara en la sección previa, en los voltamperogramas obtenidos en presencia de la mezcla de antocianinas se observa una contribución anódica a $1.3 \mathrm{~V}$, con su pico catódico correspondiente a 0.6 V. De acuerdo a la bibliografía corresponderían al comportamiento redox de los grupos $\mathrm{OH}$ de las antocianinas en un proceso que tiene lugar en dos etapas. $\mathrm{El} \mathrm{OH}$ se adsorbe a la superficie del electrodo de trabajo para luego oxidarse a potenciales más altos. La adsorción de estos grupos funcionales ocurre a potenciales más bajos que la del etanol, inhibiendo la oxidación del solvente (Kremer, et al., 2008).

Un potencial de oxidación de $1.3 \mathrm{~V}$ es un valor adecuado para el uso de las antocianinas como sensibilizadores de la celda, ya que permitiría, por un lado, la transferencia electrónica hacia el semiconductor de $\mathrm{TiO}_{2}$ y, por otro, su regeneración por la cupla presente en el electrolito (Enciso, et al., 2013).

\section{Estudios de estabilidad}

El incremento de la absorbancia con la temperatura se debe a la interacción electrostática planar en los grupos cromóforo de las antocianinas, fenómeno denominado copigmentación. El ión flavilio es casi planar y muestra una deslocalización electrónica que se extiende por todo el grupo cromóforo, y es el responsable de la copigmentación (Rustoni, et al., 2012).

Posteriormente, a partir de $60{ }^{\circ} \mathrm{C}$ el fenómeno de copigmentación ya no ocurre y por tanto se observa una meseta en los valores de absorbancia. Asimismo, no ocurre la degradación del pigmento en el rango de temperaturas de $60{ }^{\circ} \mathrm{C}$ a $90{ }^{\circ} \mathrm{C}$, reacción en la que las antocianinas devienen en chalconas, las cuales son incoloras. Dado que luego de la 
exposición a altas temperaturas no se observan pérdidas en la intensidad del color del pigmento, puede afirmarse la gran estabilidad térmica de las antocianinas del ceibo.

El aumento en los valores de absorbancia al incrementar la concentración de $\mathrm{NaI}$ se debe a que el catión $\mathrm{Na}^{+}$puede formar complejos con las antocianinas que contienen grupos hidroxilos en el anillo fenólico y de esta manera incrementar la intensidad de color del pigmento.

Por lo tanto, en las condiciones de armado de una celda, las antocianinas muestran un excelente comportamiento frente a su posible uso como sensibilizadores, ya que su capacidad de absorber la luz no se ve afectada por la presencia del solvente, la cupla o el aumento de temperatura.

\section{Estudios de impedancia}

Las medidas electroquímicas usando esta técnica permiten evaluar los cambios asociados a la transferencia de electrones que ocurren en una celda de tipo DSSC en funcionamiento. Si una celda contiene los componentes adecuados, es decir, contiene un sensibilizador capaz de transferir electrones al ser excitado por la luz, y luego es capaz de regenerarse a través de la cupla $\mathrm{I}-\mathrm{I}_{3}{ }^{-}$, esto debe verse a través de los cambios observados en presencia de luz en los valores de resistencia y capacidad de los elementos del circuito equivalente utilizado para modelar la celda.

El comportamiento observado en la celda en condiciones de luz respecto a las medidas realizadas en oscuridad está de acuerdo a lo esperado: si el pigmento es capaz de transferir electrones al semiconductor luego de ser excitado con la luz, la resistencia de transferencia de carga debe disminuir.

\section{Conclusiones}

A partir de los resultados obtenidos por voltamperometría cíclica se determinó que la transferencia electrónica desde el estado excitado del pigmento de la flor del ceibo (Erythrina crista-galli) a la banda de conducción del semiconductor podría ser posible, por presentar un potencial de oxidación suficientemente alto con respecto al $\mathrm{TiO}_{2}(0.53 \mathrm{~V})$ (Gao, et al., 2008). Este hecho, así como la regeneración del pigmento por la cupla, se verificó con las medidas de impedancia electroquímica al utilizar este pigmento como sensibilizador en el armado de una celda DSSC

Asimismo, las antocianinas presentes mostraron una buena estabilidad frente a los diferentes parámetros a los cuales están expuestas al formar parte de la celda: la temperatura, el soluto (NaI) y el solvente (etilenglicol) del electrolito.

En resumen, el pigmento proveniente de la flor del ceibo constituye un buen sensibilizador debido a su absorbancia en el visible, a su estabilidad frente a parámetros físicos y químicos, así como a su gran flexibilidad en la adaptación a nivel molecular, así como a los grupos funcionales que posee y que le permiten su anclado al semiconductor.

\section{Reconocimientos}

Se agradece a las instituciones nacionales que financiaron este proyecto de investigación, a la Agencia Nacional de Investigación e Innovación (ANII), a la Comisión Sectorial de Investigación Científica (CSIC) y a PEDECIBA Química.

\section{Referencias}

Abal, G., D’Angelo, M., Cataldo, J., y Gutierrez, A., 2011. Mapa solar del Uruguay. Versión 1.0. Memoria técnica [En línea]. Montevideo: Universidad de la República.[Consulta: abril de 2014] Disponible en: http://www.fing.edu.uy/if/solar/ memoria-mapa-solar-v1.pdf

Akond, A. S., Khandaker, L., Berthold, J. y Gates, L., 2011. Anthocyanin, total polyphenols and antioxidant activity of common bean. En: American Journal of Food Technology, 6(5), pp.385-394.

Al-Bat'hi, S. A., Alaei, I. y Sopyan, I., 2013. Natural photosensitizers for dye sensitized solar cells. En: International Journal of Renewable Energy Research, 3(1), pp.138-143.

Bisquert, J., Cahen, D., Hodes, G., Rühle, S, Zaban, A., 2004. Physical chemical principles of photovoltaic conversion with nanoparticulate, Mesoporous Dye-Sensitized solar cells. En: The Journal of Physical Chemistry B, 1088(24), pp.8106.

Brumbach, M. T., Boal, A. K. y Wheeler, D. R., 2009. Metalloporphyrin assemblies on pyridine-functionalized titanium dioxide. En: Langmuir, 25(18), pp.10685-90.

Calogero, G. y Di Marco, G., 2008. Red sicilian orange and purple eggplant fruits as natural sensitizers for dyesensitized solar cells. En: Solar Energy Materials \& Solar Cells, 92(11), pp.1341-1346.

Calogero, G., Yum, H. J., Sinopoli, A., Di Marco, G., Grätzel, M. y Nazeeruddin, M. K., 2012. Anthocyanins and betalains as light-harvesting pigments for dye-sensitized solar cells. En: Solar Energy, 86(5), pp.1563-1575.

Cao, Y. M., Bai, Y., Yu, Q. J., Cheng, Y. M., Liu, S., Shi, D., Gao F. y Wang P, 2009. Dye-sensitized solar cells with a high absorptivity ruthenium sensitizer featuring a 2-(Hexylthio)thiophene conjugated bipyridine. En: Journal of Physical Chemistry C, 113(15), pp.6290-6297.

Chen, C. Y., Wang, M. K., Li, J. L., Pootrakulchote, N., Alibabaei, L., Ngoc-le, C. H., Decoppet, J. D, Tsai, J. H., Grätzel, C., Wu, C. G., Zakeeruddin, S. M., y Grätzel, M., 2009. Highly efficient light-harvesting ruthenium sensitizer for thin-film dye-sensitized solar cells. En: ACS Nano, 3(10), pp.3103-3109.

Dwivedi, C., Dutta, V., Chandiran, A. K., Nazeeruddin, M. K. y Grätzel, M., 2013. Anatase $\mathrm{TiO}_{2}$ hollow microspheres fabricated by continuous spray pyrolysis as a scattering layer in dye-sensitised solar cells. En: Energy Procedia, 33, pp.223-227.

Enciso, P., Cabrerizo, F. M., Gancheff, J. S., Denis, P. A. y Cerdá, M. F., 2013. Phycocyanin as potential natural dye for its use in photovoltaic cells. En: The Journal of Solution Chemistry and Modeling, 2(1), pp.225-233.

Fabregat-Santiago, F., Bisquert, J., Garcia-Belmonte, G., Boschloo, G. y Hagfeldt, A., 2005. Influence of electrolyte in transport and recombination in dye-sensitized solar cells studied by impedance spectroscopy. En: Solar Energy Materials \& Solar Cells, 87(4), pp.117-131.

Fukuri, N., Masaki, N., Kitamura, T., Wada Y. y Yanagida, S., 2006. Electron transport analysis for improvement of solid-state dye-sensitized solar cells using poly(3,4ethylenedioxythiophene) as hole conductors. En: J. Phys. Chem. B, vol. 110(50), pp.25251-8.

Gao, F., Wang, Y., Shi, D., Zhang, J., Wang, M. K., Jing, X. Y., Humphry-Baker R., Wang, P., Zakeeruddin, S. M. y Grätzel, M., 2008. Enhance the optical absorptivity of 
nanocrystalline $\mathrm{TiO}_{2}$ film with high molar extinction coefficient ruthenium sensitizers for high performance dye-sensitized solar cells. En: Journal of American Chemical Society, 130(32), pp.10720-10728.

Grätzel, C. y Zakeeruddin, S. M., 2013. Recent trends in mesoscopic solar cells based on molecular and nanopigment light harvesters. En: Materials Today, 16(2), pp.11-18.

Gross, J.,1987. Pigments in fruits. Liverpool: Academic press. ISBN: 0123042003.

Hao, S., Wu, J., Huang, Y. y Lin, J., 2006. Natural dyes as photosensitizers for dye-sensitized solar cell. En: Solar Energy, 80(2), pp.209-214.

Howie, W. H., Claeyssens, F., Miura H. y Peter, L. M., 2008. Characterization of solid-state dye-sensitized solar cells utilizing high absorption coefficient metal-free organic dyes. En: Journal of the American Chemical Society, 130 (4), pp.1367-1375.

Imahori, H., Hayashi, S., Umeyama, T., Eu, S., Oguro, A., Kang, S., Matano, Y., Shishido, T., Ngamsinlapasathian, S., y Yoshikawa, S., 2006. Comparison of electrode structures and photovoltaic properties of porphyrin-sensitized solar cells with $\mathrm{TiO} 2$ and $\mathrm{Nb}, \mathrm{Ge}, \mathrm{Zr}$-Added $\mathrm{TiO}_{2}$ composite electrodes. En: Langmuir, 22(26), pp.11405-11411.

Ito, S., Chen, P., Comte, P., Nazeeruddin, M. K., Liska, P., Pechy P., y Gratzel, M., 2007. Fabrication of screen-printing pastes from $\mathrm{TiO}_{2}$ powders for dye-sensitised solar cells. En: Progress in Photovoltaics: Research and Applications, 15(7), pp.603-612.

Ito, S., Dharmadasa, I. M., Tolan, G. L., Roberts, S. J., Hill, G., Miura, H., Yum, J. H., Pechy, P., Liska, P., Comte, P. y and Grätzel, M., 2011. High-voltage (1.8 V) tandem solar cell system using a GaAs/AlXGa(1-X) As graded solar cell and dye-sensitised solar cells with organic dyes having different absorption spectra. En: Solar Energy, 85(6), pp.1220-1225.

Klahr, B. M. y Hamann, T. W., 2009. Performance enhancement and limitations of cobalt bipyridyl redox shuttles in dye-sensitized solar cells. En: The Journal of Physical Chemistry C, 113(31), pp.14040-14045.

Kremer, C., Cerdá, M. F., Torres, J., Heinzen, H., Bertucci, A., y Domínguez, S., 2008. Electrochemical behavior of flavonoids in the presence of metal ions. En: Hughes, J. G., Robinson, A. J. Inorganic biochemistry: research progress. New York: Nova Science Publishers. pp.161-184.

Li, Y., Ku, S. H., Chen, S. M., Ajmal Ali, M. y AlHemaidFahad M. A., 2013. Photoelectrochemistry for red cabbage extract as natural dye to develop a dye-sensitized solar cells. En: International Journal of Electrochemical Science, 8(1), pp.1237-1245.

Mazza, G. y Miniati, E., 1993. Anthocyanins in fruits, vegetables and grains. En: Molecular Nutrition, 38(3), p. 343.

Miño, J. y Ferraro, G., 2002. Actividad antinociceptiva y antiinflamatoria de Erythrina crista-galli L. («Ceibo»). En: Acta Farm. Bonaerense, 21(2), pp.93-98.

Mitscher, L., Gollapudi, D., Gerlach, D. y Ward, J. 1988.
Erycristin, a new antimicrobial petrocarpa from Erythrina crista galli. En: Photochemistry, 27(2), pp.381-385.

O`Reagan, B. C., Durrant, J.R. y Bakker, N. J., 2007. Influence of the $\mathrm{TiCl}_{4}$ treatment on nanocrystalline $\mathrm{TiO}_{2}$ films in dye-sensitized solar cells. 2. charge density, band edge shifts, and quantification of recombination losses at short circuit. En: The Journal of Physical Chemistry C, 111(37), pp.14001-14010.

Rabino, I. y Mancinelli, A. L., 1986. Light, temperature and anthocyanin production. En: Plant Physiology, 81, pp.922-924.

Rustoni, L., Bedgood, D. R., Failla, O., Prenzeld, P. D. y Robards, K., 2012. Copigmentation and anticopigmentation in grape extracts studied by spectrophotometry and post-column-reaction HPLC. En: Food Chemistry, 132(4), pp.2194-2201.

Scogin, R., 1991. Anthocyanins of the Genus Erythrina (Fabaceae). En: Biochemical

Systematics and Ecology, 19, pp.329-332.

Scott, M. J., Nelson, J.J., Caramori, S., Bignozzi, C. A. y Elliot, C. M., 2007. Cis-Dichloro-bis (4,4'-dicarboxy-2,2bipyridine) osmium(II)- modified optically transparent electrodes: application as cathodes in stacked dyesensitized solar cells. En: Inorganic Chemistry, 46(24), pp.10071-10078.

Smestad, G. P., 1998. Education and solar conversion: demonstrating electron transfer. En: Solar Energy Materials and Solar Cells, 55(1), pp.157-178.

Uruguay. Ley 17283, de 28 de noviembre de 2000. Diario Oficial, 12 de diciembre de 2000, p. 932.

Uruguay. Decreto 173/010, de 1 de junio de 2010. Diario Oficial, 8 de junio de 2010, p.1103.

Wang, P., Yu, Q. J., Wang, Y. H., Yi, Z. H., Zu, N. N., Zhang, J. y Zhang, M., 2010. High-efficiency dye-sensitized solar cells: The influence of lithium ions on exciton dissociation, charge recombination, and surface states. En: ACS Nano, 4(10), pp.6032-6038.

Yella, A., Lee, H-L., Tsao, H. N., Yi, C., Chandiran, A. K., Nazeeruddin, S. M., Diau, W., Yeh, C., S. M. Zakeeruddin, S. M. y Grätzel, M., 2011. Porphyrin-sensitized solar cells with cobalt (II/III)-based redox electrolyte exceed 12 percent efficiency. En: Science, 334 (6056), pp.629-634.

Yoshitama, K., 1987. An acylated delphinidin-3-rutinoside$5,3^{\prime}, 5^{\prime}$-triglucoside from Lobelia erinus. En: Phytochemistry, 16(11), pp.1857-1858.

Yum, J. H., Moon, S. J., Karthikeyan, C., Wietasch, S. H., Thelakkat, M., Zakeeruddin S. M., Nazeeruddin, M. K. y Grätzel, M., 2012. Heteroleptic ruthenium complex containing substituted triphenylamine hole-transport unit as sensitizer for stable dye-sensitized solar cell. En: Nano Energy, 1(1), pp.6-12.

Zhou, H., Wu, L., Gao, Y. y Ma, T., 2011. Dye-sensitized solar cells using 20 natural dyes as sensitizers. En: Journal of Photochemistry and Photobiology A: Chemistry, 219(3), pp.188-194. 